\title{
Radio frequency heating for corn seeds: Model development and uniformity optimization
}

\author{
Shuo Wei ${ }^{1}$, Fenghe Wang ${ }^{1}$, Ben Fan ${ }^{1}$, Deyong Yang ${ }^{1 *}$ \\ ${ }^{1}$ College of Engineering, China Agricultural University, 100083 Beijing, China
}

\begin{abstract}
Radio frequency (RF) heating has been considered as a promising method for food pasteurization and disinfestations, materials and heating uniformity are the main considerations in developing and scaling-up RF treatment protocols. In this study, an experimentally validated model of corn seeds was developed to investigate its RF heating characteristics and effects of sample shape on heating uniformity. Results showed that hot spots distributed in the corners and edges but cold ones in the centre of the rectangular sample, which led to the concentration of electric field at the sample edges, thus increased their electric field intensity and loss power. Comparing the temperature distributions of corn samples in six shapes, the best heating uniformity was observed in the special round sample (round corners, edges and surfaces), its uniformity index was 0.04 , as its special round surface made the direction of the electromagnetic field in the sample incline to the centre, and homogenized the electric field intensity and loss power density. The results provide an evidence for temperature prediction and uniformity improvement of corn seeds during RF heating.
\end{abstract}

\section{Introduction}

Corn is one of the most primary food crops in terms of both large yield and wide use in the world. It is reported that there are great postharvest losses of corn every year, especially for developing countries, the majority of losses are mainly due to the invasion of insect and mold resulting from poor postharvest storage management, which is becoming major concerns [1-3]. Since it is difficult to increase cereal yield due to the limited farmland, it is of a great value to develop a postharvest processing method to protect corn seeds from insect and mold contamination during storage.

Various methods have been used to control the invasion of insect and mold before grain storage. The physical methods, such as hot air, plasma, ultraviolet (UV), infrared (IR), microwave and RF heating [4-5], are widely acceptable when considering the negative environmental pollutions and human health of chemical fumigation [6-7]. Among them, microwave and RF heating have the advantages of rapid, volumetric and selective heating [8], which provide an ideal processing condition for short-time pasteurization and insect deactivation of cereals. Furthermore, for insects, whose dielectric constant and loss factor are larger than those of low moisture grains, their temperatures increase faster than those of agricultural products and reach their lethal temperatures firstly during RF heating, thus, avoids the damage of high temperature treatment to the products [910]. The difference is that the penetration depth of RF energy is larger than that of microwave [11-12], thus, RF heating has great potential in term of large-scale thermal processing of grains.

Despite the advantages of RF heating, the heating uniformity is the mainly limitation in the current application [13-14]. Many effective measures have been taken to improve the uniformity of RF heating in agricultural products, such as equipment improvement, heating parameter adjustment, sample movement or rotation, container or packaging optimization, etc. [1517], where the optimization of container or sample shape is a more practical and less costly method. Huang et al. [18] reported that the container with round corners could provide better heating uniformity for soybeans than rectangular container, and Alfaifi et al. [19] found that rounding the corners and edges of sample could further improve the RF heating uniformity. While, there were still hot spots at the surface or inner of sample.

Computer simulation is a flexible and cost-effective method to obtain detail information that is difficult to measure due to the electric field and help understand the mechanism of RF heating, also provides a guide to improve RF heating uniformity [14]. Generally, Maxwell's equations and heat transfer equation based RF heating models are developed to study the distributions of temperature, electric field or loss power for various agricultural products [19-20], such as soybeans [18], wheat [21], peanuts [22], and bulk chestnuts [23]. To the best of our knowledge, there are few reports about the development of RF heating model for corn seeds.

The objectives of this study were to (1) develop the RF heating model for corn seeds, (2) analyse the RF

*Corresponding author: ydy@cau.edu.cn 
heating characteristics by electric field and power density, (3) improve the RF heating uniformity by adjusting the sample shapes.

\section{Materials and methods}

\subsection{Materials}

Corn seeds (Zhengdan 958) were purchased from a local market in Beijing, China. The initial moisture content of corn seeds was $9.75 \pm 0.3 \%$ (w.b.) determined by the oven drying method [24]. Enough corn seeds (10 kg) were kept at room temperature $\left(25 \pm 0.5^{\circ} \mathrm{C}\right)$ for $4 \mathrm{~h}$ before tests.

\subsection{RF heating experiment}

A $6 \mathrm{~kW}, 27.12 \mathrm{MHz}$ free-running oscillator RF heating system (SO6B, Stray field International Limited, Wokingham, U.K, Fig. 1) was used in this study. $230 \mathrm{~g}$ of corn seeds were filled into a rectangular polypropylene container (Fig. 2), which was placed in the middle of two electrodes in the RF system. The electrode gap was fixed at $11 \mathrm{~cm}$ based on preliminary tests. The real-time temperature of corn seeds was monitored at each $6 \mathrm{~s}$ by an eight-channel fiber optical temperature sensor system (Umi8, Fiso Technologies Inc., Quebec, Canada) during RF heating process, which was inserted into the corner, edge and centre of the rectangular container. The surface temperatures of corn seeds were recorded by an infrared camera (Ti55FT, Fluke electronic instrument and instrument company, Washington, USA). The heating experiment was performed in triplicate.

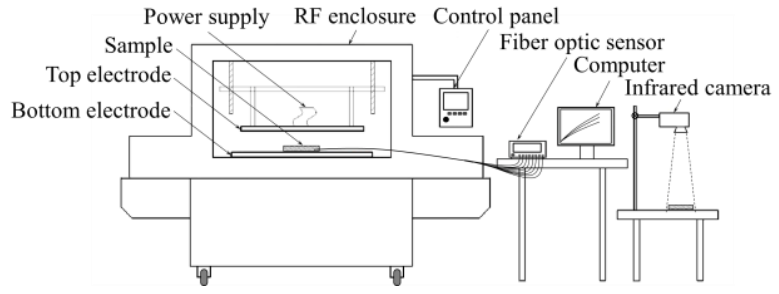

Fig. 1. Radio frequency heating system

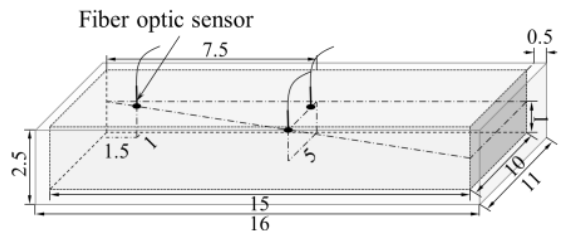

Fig. 2. Position (corner, edge and centre) of three optical fiber temperature sensors in the rectangular container (all dimensions are in $\mathrm{cm}$ ).

\subsection{Computer simulation}

\subsubsection{Assumptions}

The following assumptions were considered for developing the solution scheme for the RF heating model of corn kernels:

(1) The initial temperature of bulk corn kernels in the container was uniformly distributed.

(2) The evaporation and dissipation of moisture in corn seeds during RF heating were not considered.

(3) Bulk corn seeds in the rectangular container were regarded as virtual continuous media.

\subsubsection{Physical geometry model}

As shown in Fig. 3a and Fig. 3b, the three-dimensional (3D) geometric model of corn seeds treated by RF heating could be simplified into main heating cavity $\left(129 \mathrm{~L} \times 109 \mathrm{~W} \times 74 \mathrm{H} \mathrm{cm}^{3}\right)$, top electrode $\left(83 \mathrm{~L} \times 40 \mathrm{~W} \mathrm{~cm} \mathrm{~cm}^{2}\right.$, bottom electrode $\left(99 \mathrm{~L} \times 59 \mathrm{~W} \times 10 \mathrm{H} \mathrm{cm}^{3}\right)$, rectangular polypropylene container and bulk corn seeds according to their actual size.

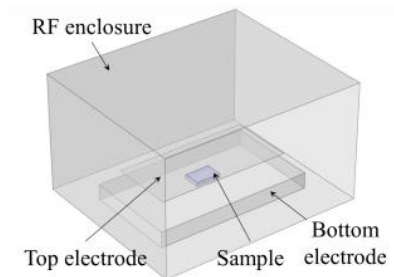

(a)

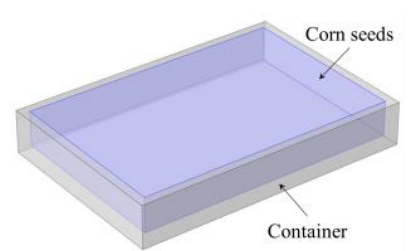

(b)
Fig. 3. Geometrical model of (a) RF heating system and (b) bulk corn seeds filled with container used in simulation.

\subsubsection{Governing equations}

Electromagnetic field distribution of RF heating system could be described by Maxwell's equations of electromagnetism in differential forms [20]. Since the wave length $(11 \mathrm{~m})$ in the $27.12 \mathrm{MHz} \mathrm{RF}$ system was much longer than the size of RF heating cavity and electrode in this study, Maxwell's electromagnetic field equations could be solved by a quasi-static approximation for the electric current model, which could be expressed as [25]:

$$
-\nabla \cdot\left(\left(\sigma+j 2 \pi f \varepsilon_{0} \varepsilon^{\prime}\right) \cdot \nabla V\right)=0
$$

Where $\sigma$ is electrical conductivity of sample or surrounding air $\left(\mathrm{S} \cdot \mathrm{m}^{-1}\right), j=\sqrt{-1}, f$ is the frequency $(\mathrm{Hz})$, $\varepsilon_{0}$ is the permittivity of free space $\left(8.86 \times 10^{-12} \mathrm{~F} \cdot \mathrm{m}^{-1}\right), \varepsilon^{\prime}$ is the dielectric constant of sample or surrounding air, and $V$ is the voltage between the two electrodes $(\mathrm{V})$.

The heat transfer due to convection at sample's surface and RF heating in the sample was described by Fourier's equation [18]:

$$
\left\{\begin{array}{l}
\rho C p \frac{\partial T}{\partial t}=\nabla \cdot(k \nabla T)+Q \\
Q=2 \pi f \varepsilon_{0} \varepsilon^{\prime \prime}|\vec{E}|^{2}
\end{array}\right.
$$

Where $\rho$ is the density $\left(\mathrm{kg} \cdot \mathrm{m}^{-3}\right), C p$ is the heat capacity $\left(\mathrm{J} \cdot \mathrm{kg}^{-1} \cdot \mathrm{K}^{-1}\right), T$ is the temperature within the sample $(\mathrm{K}), t$ is the treat time $(\mathrm{s}), k$ is thermal conductivity $\left(\mathrm{W} \cdot \mathrm{m}^{-1} \cdot \mathrm{K}^{-1}\right), Q$ is the RF power dissipation $\left(\mathrm{W} \cdot \mathrm{m}^{-3}\right), \varepsilon^{\prime \prime}$ is the loss factor of sample or surrounding 
air, and $E$ is the electric field intensity $(\mathrm{V} / \mathrm{m})$ related to the voltage $(E=-\nabla V)$.

\subsubsection{Physical-thermal parameters}

Physical-thermal parameters of the bulk corn seeds and surrounding medium were given in Table 1 by reference and measurement for modeling the RF heating process.

Table 1. Dielectric and thermo-physical properties of materials used for simulation.

\begin{tabular}{lccc}
\hline Parameters & Air & Polypropylene & Corn \\
\hline Density $\left(\mathrm{kg} \cdot \mathrm{m}^{-3}\right)$ & 1.20 & 900 & 1245 \\
Bulk density $\left(\mathrm{kg} \cdot \mathrm{m}^{-3}\right)$ & - & - & 767 \\
$\begin{array}{l}\text { Heat capacity } \\
\left(\mathrm{J} \cdot \mathrm{kg}^{-1} \cdot \mathrm{K}^{-1}\right)\end{array}$ & 1200 & 1800 & 1831 \\
Thermal conductivity & 0.025 & 0.26 & Fig. 4 \\
$\left(\mathrm{W} \cdot \mathrm{m}^{-1} \cdot \mathrm{K}^{-1}\right)$ & 1 & 2 & Fig. 5a \\
Dielectric constant & 0 & 0.0023 & Fig. 5b \\
Loss factor &
\end{tabular}

Thermal conductivity was measured by a thermal conductivity analyzer (HFM 436 Lambda, NETZSCH GABO Instruments $\mathrm{GmbH}$, Selb, Germany) according to the steady-state parallel-plate heat-source method. The temperature-dependent $\left(25-85{ }^{\circ} \mathrm{C}\right)$ thermal conductivity of corn seeds is shown in Fig. 4. The thermal conductivity of bulk corn seeds could be described by the following regression equation:

$$
k=0.00001948 T^{2}-0.01067 T+1.575
$$

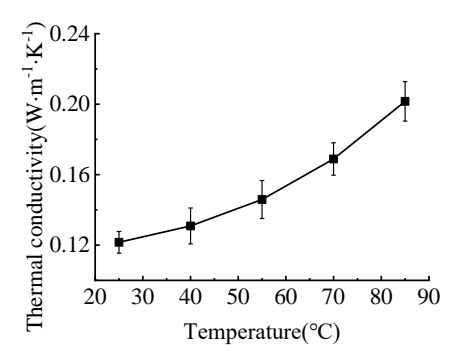

Fig. 4. Temperature-dependent thermal conductivity of corn seeds with moisture content of $9.75 \%$ (w. b.).

Dielectric properties of corn seeds at $27.12 \mathrm{MHz}$ were measured by an open-ended coaxial probe system consisting of an impedance analyzer (E4991B, Keysight Technologies Co. LTD., Palo Alto, California, USA), sample temperature was controlled by an oil circulated bath (SST-20, Guanya Constant Temperature Cooling Technology Co. LTD., Wuxi, China). Corn seeds were ground into powder (particle size $0.425 \mathrm{~mm}$ ) and compressed into cylindrical samples, whose density were consistent with the bulk density of corn seeds. Temperature-dependent $\left(25-85{ }^{\circ} \mathrm{C}\right)$ dielectric constant and loss factor of corn seeds are shown in Fig. 5a and Fig. 5b. The thermal conductivity of bulk corn seeds could be described by the following regression equations:

$$
\varepsilon^{\prime}=0.00001903 T^{3}-0.01717 T^{2}+5.178 T-518.1
$$

$\varepsilon^{\prime \prime}=0.000009411 T^{3}-0.008762 T^{2}+2.724 T-281.9$

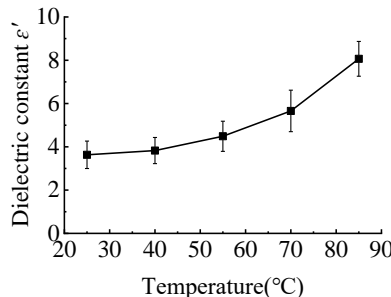

(a)

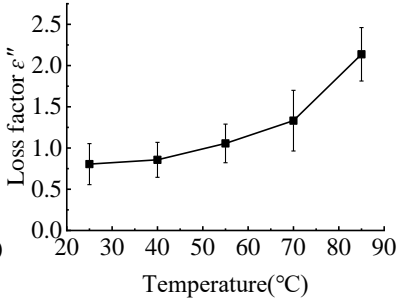

(b)
Fig. 5. Temperature-dependent (a) dielectric constant and (b) loss factor of corn seeds with moisture content of $9.75 \%$ (w. b.) at $27.12 \mathrm{MHz}$.

\subsubsection{Initial and boundary conditions}

(1) The metal enclosure boundary of RF unit was considered as thermal insulation $(\nabla T=0)$. All the metal shielding parts except for the top electrode were set as ground $(V=0)$.

(2) Electrical insulation $\nabla E=0$ was considered for the external walls of the RF cavity. The initial temperature of all domains in the system, including the air, container, sample, upper and bottom electrodes was set at room temperature $\left(T_{0}=25^{\circ} \mathrm{C}\right)$.

(3) A constant electric field was applied at the upper electrode during RF heating, so the voltage of the top electrode can be calculated by anode current $\left(I_{a}\right)$ and real-time power $(V=5600 \mathrm{~V})$.

(4)The sample surfaces were considered to be subjected to heat exchange with surrounding air during RF heating, where the convective heat transfer coefficient was $20 \mathrm{~W} \cdot \mathrm{m}^{-2} \cdot \mathrm{K}^{-1}$ according to the existing researches [18].

\subsection{Heating uniformity evaluation}

Heating uniformity index (UI) was used to evaluate the temperature uniformity of samples during RF heating, which was defined as the ratio of standard deviation to average temperature rise as follows [26]:

$$
U I=\frac{\sqrt{S D^{2}-S D_{0}^{2}}}{T-T_{0}}
$$

Where $T$ and $T_{0}$ are final and initial average temperatures of sample $\left({ }^{\circ} \mathrm{C}\right)$, and $S D$ and $S D_{0}$ are final and initial standard deviation $\left({ }^{\circ} \mathrm{C}\right)$ of sample temperatures over heating time, respectively.

\subsection{Simulation procedure}

A finite element software (COMSOL Multi-physics 5.4, Burlington, MA, USA) with the joule heating module, run by a Samsung computer with Core i5 processors, 8 GB RAM on a Windows 764 bit operating system, was used to solve the coupled electromagnetic and heat transfer equations in this study. The three-dimensional geometric model was imported and meshed into 274441 domain elements, 24810 boundary elements and 993 edge elements while satisfying certain constraints of the maximum cell size of $0.25 \mathrm{~mm}$ and growth rate of 1.5 , which ensured that the simulated results are gridindependent. The Multi-frontal Massively Parallel 
Sparse (MUMPS) direct solver was used with a relative tolerance of 0.01 and an absolute tolerance of 0.001 . As the error gradually decreased to the desired calculation error, the average time of each computation case with six-minute time step took about 9 minutes.

\section{Results and discussion}

\subsection{Verification of RF heating model}

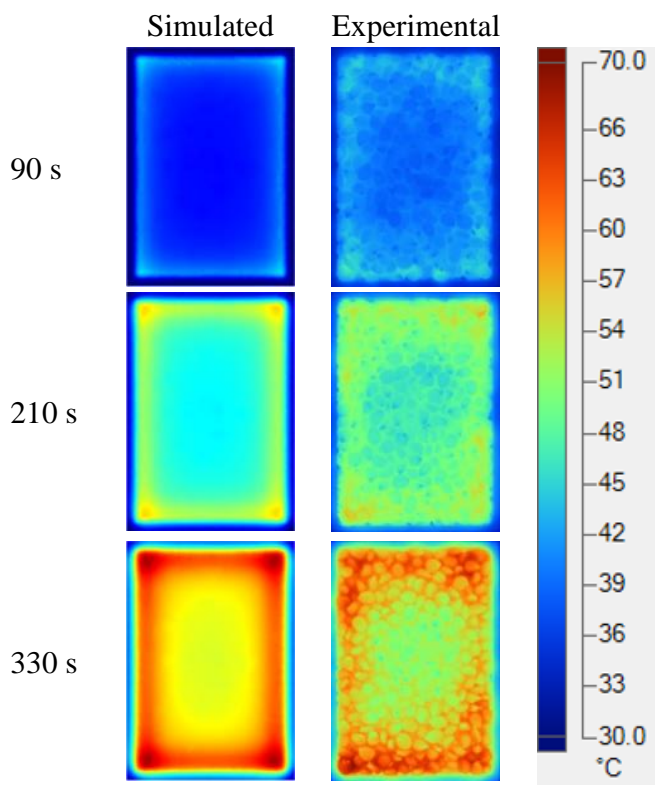

Fig. 6. Experimental and simulated temperature distributions at the surface of bulk corn seeds in the rectangular container after 90s, 210s and 330s RF heating with a fixed electrode gap of 11 $\mathrm{cm}$.

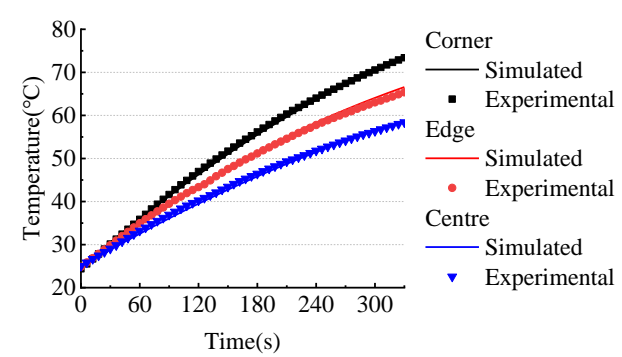

Fig. 7. Comparison of experimental and simulated temperature for bulk corn seeds in corner, edge and centre of the rectangular container during RF heating with a fixed electrode gap of $11 \mathrm{~cm}$.

Experimental and simulated temperature distributions at the surface of bulk corn seeds in the rectangular container are compared in Fig. 6. Experimental and simulated temperature distributions showed a good agreement. Both experiment and simulation presented hot spots at corners and edges but cold ones in the centre of the rectangular container. The maximum temperature differences between experiment and simulation were about $5{ }^{\circ} \mathrm{C}, 10{ }^{\circ} \mathrm{C}$, and $15{ }^{\circ} \mathrm{C}$ between corners and centres at $90 \mathrm{~s}, 210 \mathrm{~s}$ and $330 \mathrm{~s}$, respectively. Corner overheating was also found in many other materials heated by RF [14]. What's more, the experimental temperature at the corner edges and centres in the rectangular container also showed good agreements with the simulated one (Fig. 7), which was higher than that of the surface. The heating rate of corn in the corner, edge and centre were $0.15{ }^{\circ} \mathrm{C} / \mathrm{s}, 0.14{ }^{\circ} \mathrm{C} / \mathrm{s}, 0.11{ }^{\circ} \mathrm{C} / \mathrm{s}$ respectively. Overall, the temperature differences between experiment and simulation were less than $2{ }^{\circ} \mathrm{C}$, which indicated that the accuracy of model and parameters was available.

\subsection{Simulated electromagnetic field and power of bulk corn seeds}

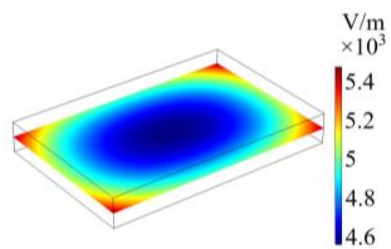

(a)

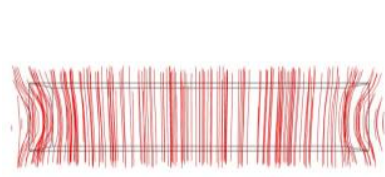

(c)

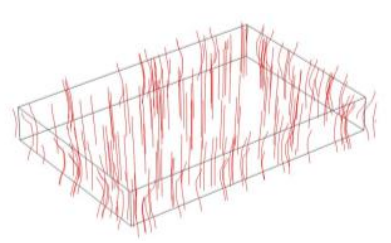

(b)

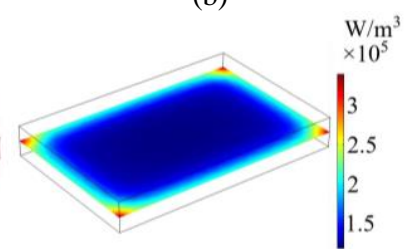

(d)
Fig. 8. Simulated (a) electric field intensity, (b and c) electric field direction and (d) power density of bulk corn seeds in the rectangular container with a fixed electrode gap of $11 \mathrm{~cm}$.

Corn seeds converted the electromagnetic energy into thermal energy during RF heating process, so it was necessary to analyze its electric field and loss power distribution [16], which was helpful to understand its heating characteristics. Fig. 8a shows the electric field intensity distributions of corn seeds in the rectangular container with a fixed electrode gap of $11 \mathrm{~cm}$. It could be observed that the electric field intensity in the centre of the container was lower, and the higher electric field intensity distributed in the edge and corner. This phenomenon could be explained by the deflection, concentration and superposition of electric field direction in the sample edges (Fig. 8b and Fig. 8c). Accordingly, as shown in Fig. 8d, the loss power density of the sample at the corner was greater than that at the centre, which well revealed the reason for the corner overheating of the rectangular sample during the RF heating process. This phenomenon has been reported in various agricultural products heated in RF systems $[10,26]$. In a word, the regions where the sample shape fluctuated greatly led to excessive electric field intensity, which also suggested the significant effects of surrounding materials (air and container) on obtaining uniform electric field distributions inside the sample [18, 27]. Compared with the dielectric parameters of the surrounding materials, the larger dielectric constant and loss factor of the sample had stronger ability to attract electromagnetic field, which was another kind of RF heating selectivity. 


\subsection{RF heating uniformity of corn sample with different shapes}

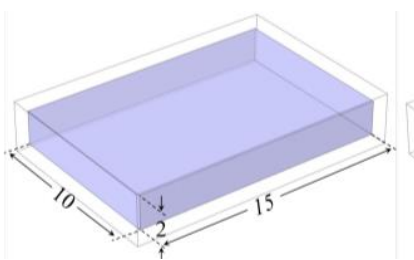

(a)

(c)

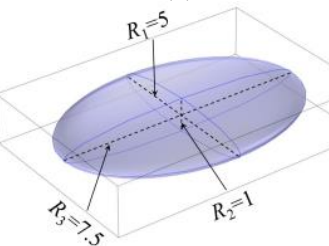

(e)

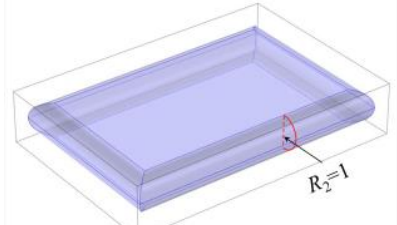

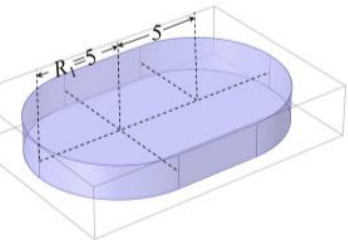

(b)

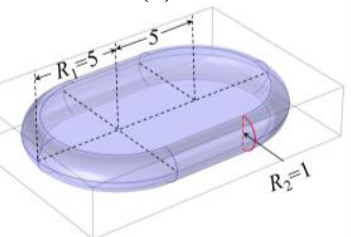

(d)

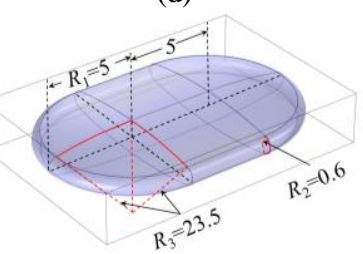

(f)
Fig. 9. Six corn sample shapes, a) rectangular $(\mathrm{Rt}), \mathrm{b})$ round corner $(\mathrm{Rc}), \mathrm{c})$ round edge $(\mathrm{Re}), \mathrm{d})$ round corner and edge (Rce), e) ellipsoid (El), f) special round ( $\mathrm{Sr}$ ), used in simulation. (all dimensions are in $\mathrm{cm}$ )

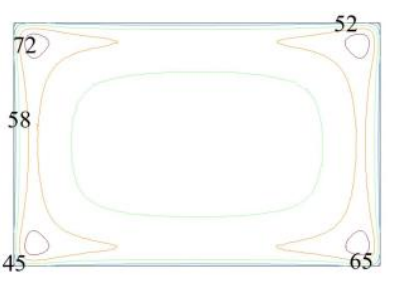

(a)

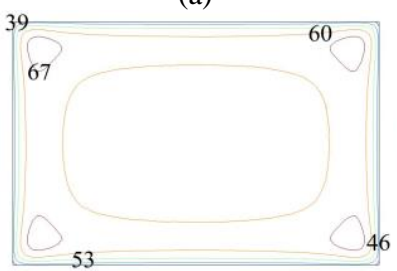

(c)

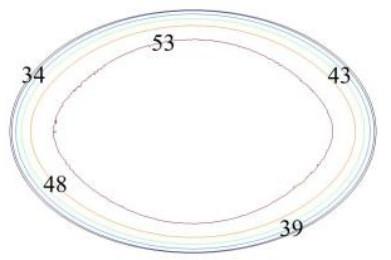

(e)

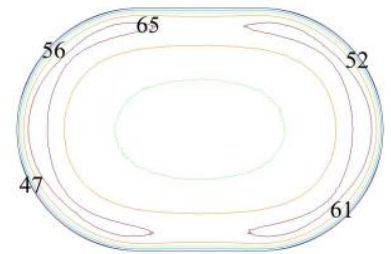

(b)

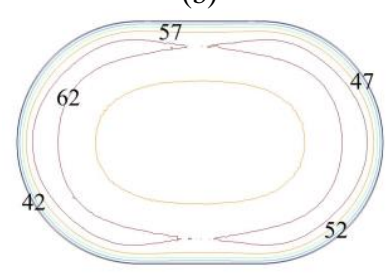

(d)

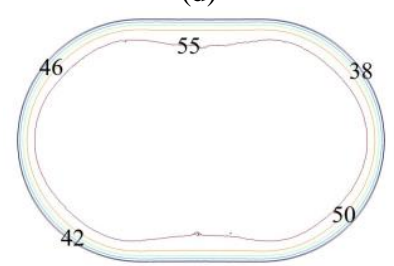

(f)
Fig. 10. Temperature $\left({ }^{\circ} \mathrm{C}\right)$ distributions of corn samples in a) rectangular $(\mathrm{Rt}), \mathrm{b})$ round corner $(\mathrm{Rc}), \mathrm{c})$ round edge $(\mathrm{Re}), \mathrm{d})$ round corner and edge (Rce), e) ellipsoid (El), f) special round

(Sr) shapes and heated to a centre temperature of $55^{\circ} \mathrm{C}$.

In order to improve the RF heating uniformity caused by the sharp shape, corn samples in rectangular, round corner, round edge, round corner and edge, ellipsoid, special round shapes were studied step-by-step (Fig 9). Since the lethal temperature of stored-grain insects were about $55{ }^{\circ} \mathrm{C}$ [28-29], the final temperature of corn samples in different shapes were heated to a centre temperature of $55{ }^{\circ} \mathrm{C}$ to compare their $\mathrm{RF}$ heating uniformity. As shown in Fig 10, the higher temperatures were observed in the regions of the edges and corners of the rectangular, round corner, round edge, round corner and edge shapes. On the contrary, the hot spot was in centre of ellipsoid sample. Similar result has been reported by Alfaifi et al. [19]. But for the special round sample, there were no hot and cold spots (Fig 10f). The details of corn samples in different shapes heated to a centre temperature of $55{ }^{\circ} \mathrm{C}$ are shown in Table 2 . It is obvious that rounding the edges or corners of the samples sharply reduced their maximum temperatures and thus the temperature differences, where the value of special round sample was minimal $\left(20.47{ }^{\circ} \mathrm{C}\right)$. In addition, the temperature difference was also caused by the heat exchange between the sample and the surrounding material. According to recommendations from Zhou and Wang [30], if the temperatures of the surrounding materials increased, the temperature difference and uniformity index of the special round sample would further reduced. Except the special round sample, the average temperatures of samples in other shapes deviated significantly from their central temperatures. Furthermore, the smallest standard deviation of temperature was also observed in the special round sample. Accordingly, the uniformity index of ellipse sample was the largest, that of other shapes was smaller than that of rectangular, and that of special round shape was the smallest only 0.04 , which was also better than the reported result [19]. It indicated that the better temperature uniformity of samples could be achieved when the sample shape was special round.

Table 2. Simulated minimum (Min), maximum (Max), average (Ave), standard deviation (SD) temperatures and uniformity index $(U I)$ of bulk corn seeds in rectangular (Rt), round corner $(\mathrm{Rc})$, round edge $(\mathrm{Re})$, round corner and edge (Rce), ellipsoid $(\mathrm{El})$, special round $(\mathrm{Sr})$ shapes and heated to a centre temperature of $55^{\circ} \mathrm{C}$.

\begin{tabular}{ccccccc}
\hline Shape & $\begin{array}{c}\text { Min } \\
\left({ }^{\circ} \mathrm{C}\right)\end{array}$ & $\begin{array}{c}\text { Max } \\
\left({ }^{\circ} \mathrm{C}\right)\end{array}$ & $\begin{array}{c}\text { Max- } \\
\text { Min } \\
\left({ }^{\circ} \mathrm{C}\right)\end{array}$ & $\begin{array}{c}\text { Ave } \\
\left({ }^{\circ} \mathrm{C}\right)\end{array}$ & $\begin{array}{c}\mathrm{SD} \\
\left({ }^{\circ} \mathrm{C}\right)\end{array}$ & $U I$ \\
\hline $\mathrm{Rt}$ & 41.46 & 75.59 & 34.13 & 60.47 & 4.84 & 0.14 \\
$\mathrm{Rc}$ & 45.43 & 67.52 & 22.09 & 60.24 & 3.94 & 0.11 \\
$\mathrm{Re}$ & 35.47 & 70.38 & 34.91 & 60.16 & 3.90 & 0.11 \\
$\mathrm{Rce}$ & 40.02 & 65.31 & 25.29 & 59.73 & 3.02 & 0.09 \\
$\mathrm{El}$ & 31.59 & 55.12 & 23.53 & 51.89 & 4.25 & 0.16 \\
$\mathrm{Sr}$ & 36.18 & 56.65 & 20.47 & 55.36 & 1.26 & 0.04 \\
\hline
\end{tabular}

The simulated electric field and loss power in the special round sample were used to analyze the reasons for the significant improvement of RF heating uniformity (Fig. 11). Obviously, compared with rectangular sample, the special round shape not only eliminated the sharp edges and corners, but also changed the angle between the electric field direction and the surface of the sample (Fig. 11a and 11b). Thus, the direction of the electromagnetic field in the sample inclines to the centre, which avoided the electric field gathering in the edge, and increased the electric field 
intensity in the centre of the sample (Fig. 11c). Similar trends were observed in the distribution of loss power density (Fig. 11d). Therefore, the essence of improving the RF heating uniformity by adjusting sample shape is to homogenize the electric field intensity in the whole sample, not the local corners and edges.

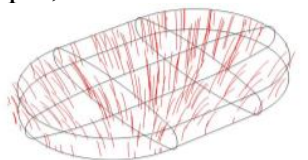

(a)

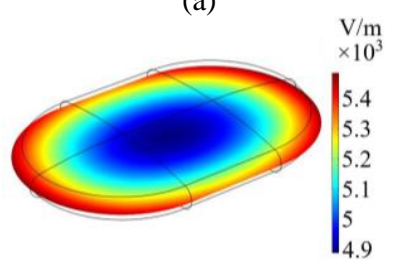

(c)

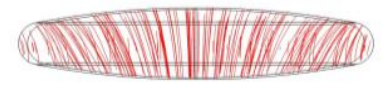

(b)

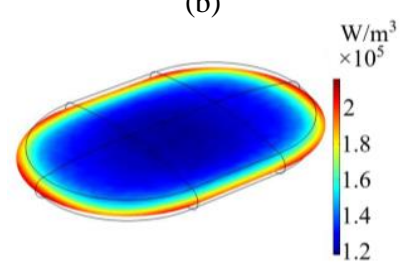

(d)
Fig. 11. Simulated (a and b) electric field direction, (c) electric field intensity and (d) power density of the special round shape with a fixed electrode gap of $11 \mathrm{~cm}$.

\section{Conclusion}

A RF heating model was developed for bulk corn seeds at a $6 \mathrm{~kW}, 27.12 \mathrm{MHz}$ RF heating system. Simulated temperature was in good agreement with experimental temperature. The temperature distribution of corn seeds filled in a rectangular container is not uniform during RF heating, showing over-heating at corners and edges, which was caused by the concentration of electric field at the sample edges thus increases their electric field intensity and loss power. Comparing the temperature distributions of corn samples in rectangular, round corner, round edge, round corner and edge, ellipsoid, and special round shapes, the best heating uniformity was distributed in the special round sample, only 0.04 , whose special round surface changed the angle between the electric field direction and the surface of the sample. As a result, the direction of the electromagnetic field in the sample inclines to the centre, which homogenized the electric field intensity and loss power density accordingly. The results provide an evidence for temperature prediction and uniformity improvement of corn seeds during RF heating.

\section{Acknowledgments}

This study was supported by research grants from the National Natural Science Foundation of China (No. 31171772).

\section{References}

1. J.R. Mendoza, C.R. Kok, J. Stratton, A. Bianchini, H.E. Hallen-Adams, Crop Protection, 101 (2017a).

2. J.R. Mendoza, L. Sabillón, W. Martinez, C. Campabadal, H.E. Hallen-Adams, A. Bianchini, J. Stored Prod. Res. 71 (2017b).

3. D. Kumar, P. Kalita, Food. 6 (2017).
4. C. Hertwig, K. Reineke, J. Ehlbeck, D. Knorr, O. Schluter, Food Control, 55 (2015).

5. Zheng, B. Zhang, L. Zhou, S. Wang, J. Stored Prod. Res. 68 (2016).

6. S. Wang, J. Tang, R.P. Cavalieri, Postharvest Biol. Technol. 22 (2001).

7. K. Lorenz, B.S. Miller, Crit. Rev. Food Sci. Nutr. 6 (1975).

8. R.J. Macana, O.D. Baik, Food Rev. Int. 34 (2018).

9. B. Shrestha, O. Baik, Eng. Agric., Environ. food, 12 (2019).

10. Z. Huang, L. Chen, S. Wang, Int. J. Heat Mass Transf. 90 (2015).

11. S. Wang, J. Tang, J.A. Johnson, E. Mitcham, J.D. Hansen, G. Hallman, S.R. Drake, Y. Wang, Biosyst. Eng. 85 (2003).

12. S. Zhang, L. Zhou, B. Ling, S. Wang, Biosyst. Eng. 145 (2016).

13. Priyadarshini, G. Rajauria, C.P. Odonnell, B.K. Tiwari, Crit. Rev. Food Sci. Nutr. 59 (2019).

14. Z. Huang, F. Marra, J. Subbiah, S. Wang, Crit. Rev. Food Sci. Nutr. 58 (2018).

15. S. Wang, J. Yue, J. Tang, B. Chen, Postharvest Biol. Technol. 35 (2005).

16. G. Tiwari, S. Wang, J. Tang, S. Birla, J. Food Eng. 104 (2011).

17. T.K. Palazoglu, W. Miran, Innov. Food Sci. Emerg. Technol. 47 (2018).

18. Z. Huang, B. Zhang, F. Marra, S. Wang, Innov. Food Sci. Emerg. Technol. 33 (2016).

19. B. Alfaifi, J. Tang, B. Rasco, S. Wang, S.S. Sablani, Innov. Food Sci. Emerg. Technol. 37 (2016).

20. H. Zhu, D. Li, J. Ma, Z. Du, P. Li, S. Li, S. Wang, Innov. Food Sci. Emerg. Technol. 47 (2018).

21. S. Jiao, Y. Deng, Y. Zhong, D. Wang, Y. Zhao, Food Res. Int. 71 (2015).

22. S. Zhang, Z. Huang, S. Wang, Innov. Food Sci. Emerg. Technol. 41 (2017).

23. L. Hou, Z. Huang, X. Kou, S. Wang, Food Bioprod. Process. 100 (2016).

24. AOAC, 2002.

25. A.C. Metaxas, Fuel Energy Abstracts, 3 (1996).

26. L. Chen, K. Wang, W. Li, S. Wang, Comput. Electron. Agric. 118 (2015).

27. Y. Jiao, J. Tang, S. Wang, J. Food Eng. 141 (2014).

28. M.C. Lagunas-Solar, Z. Pan, N.X. Zeng, T.D. Truong, R. Khir, K.S.P. Amaratunga, Trans. ASABE. 23 (2007).

29. S.M.H. Mirhoseini, M. Heydari, A. Shoulaie, J. Biol. Sci. 9 (2009).

30. X. Zhou, S. Wang, Drying Technol. 37 (2019). 